\title{
Flexible ITO-Free Roll-Processed Large-Area Nonfullerene Organic Solar Cells Based
} on P3HT:O-IDTBR

\author{
Fernández Castro, Marcial; Mazzolini, Eva; Søndergaard, Roar R.; Espindola Rodriguez, Moises; \\ Andreasen, Jens Wenzel
}

Published in:

Physical Review Applied

Link to article, DOI:

10.1103/PhysRevApplied.14.034067

Publication date:

2020

Document Version

Publisher's PDF, also known as Version of record

Link back to DTU Orbit

Citation (APA):

Fernández Castro, M., Mazzolini, E., Søndergaard, R. R., Espindola Rodriguez, M., \& Andreasen, J. W. (2020). Flexible ITO-Free Roll-Processed Large-Area Nonfullerene Organic Solar Cells Based on P3HT:O-IDTBR. Physical Review Applied, 14(3). https://doi.org/10.1103/PhysRevApplied.14.034067

\section{General rights}

Copyright and moral rights for the publications made accessible in the public portal are retained by the authors and/or other copyright owners and it is a condition of accessing publications that users recognise and abide by the legal requirements associated with these rights.

- Users may download and print one copy of any publication from the public portal for the purpose of private study or research.

- You may not further distribute the material or use it for any profit-making activity or commercial gain

- You may freely distribute the URL identifying the publication in the public portal 


\title{
Flexible ITO-Free Roll-Processed Large-Area Nonfullerene Organic Solar Cells Based on P3HT:O-IDTBR
}

\author{
Marcial Fernández Castro $\odot,{ }^{\dagger}$ Eva Mazzolini®$\odot,{ }^{\dagger}$ Roar R. Sondergaard, Moises Espindola-Rodriguez $\odot,{ }^{*}$ \\ and Jens Wenzel Andreasen 1 \\ Department of Energy Conversion and Storage, Technical University of Denmark, Kgs. Lyngby DK-2800, \\ Denmark
}

(Received 12 January 2020; revised 8 June 2020; accepted 15 June 2020; published 29 September 2020)

\begin{abstract}
The mark of $18 \%$ power conversion efficiency (PCE) was recently overcome by laboratoryscale organic solar cells (OSCs) thanks to the development of nonfullerene acceptors (NFAs). NFA-based solar cells show improved performance and stability compared with those of their fullerene-acceptor-based counterparts. However, only a few studies focus on scalable deposition techniques or roll-to-roll compatible processing, which is of paramount importance for the commercialization of the technology. Here, we report a simple and fast fabrication of slot-die-coated poly(3-hexylthiophene-2,5-diyl):(5Z,5' Z)-5,5' - $\left\{\left[7,7^{\prime}-(4,4,9,9\right.\right.$-tetraoctyl-4,9-dihydro-s-indaceno[1,2-b:5, 6-b']dithiophene-2,7-diyl)bis(benzo[c][1,2,5]thiadiazole-7,4-diyl)]bis(methanylylidene)\}bis(3-ethyl-2-thi oxothiazolidin-4-one) (P3HT:O-IDTBR) OSCs using a roll platform on flexible ITO-free substrates under ambient conditions. We show that the optical band gap of the active layer increases when an isopropanoldiluted poly(3,4-ethylenedioxythiophene):polystyrene sulfonate (PEDOT:PSS) hole-transport layer is coated on top of it, changing the device properties. Optimization of the coating conditions leads to the achievement of up to $3.6 \%$ PCE for single cells of $1 \mathrm{~cm}^{2}$ fabricated under ambient conditions with flexographic printed Ag back electrodes, compared with solar cells with evaporated Ag (3.8\% PCE), Au (2.1\% PCE), or $\mathrm{Cu}\left(3.0 \%\right.$ PCE) back contacts. OSCs with larger areas of $4 \mathrm{~cm}^{2}$ with $2.3 \%$ PCE are also fabricated, where the fast increase of the series resistance with the area is the main PCE-limiting factor. The efficiencies herein reported for NFAs obtained by roll processing show the excellent potential of the P3HT:O-IDTBR blend for large-scale fabrication.
\end{abstract}

DOI: 10.1103/PhysRevApplied.14.034067

\section{INTRODUCTION}

Organic solar cells (OSCs) have been under the spotlight thanks to their short energy payback times and the possibility of being solution-processed at high speeds and under ambient conditions, using roll-to-roll manufacturing [1,2].

Usually, donor-acceptor (D-A) materials are the starting point to improve the efficiency and stability of OSCs. A proper D-A blend combination can lead to an optimized morphology, resulting in improved photovoltaic parameters [3-8].

Fullerene derivatives are some of the most researched electron-acceptor materials of recent decades. However, the efficiency achieved for single-junction fullerene-based devices has leveled out at around 10\% [9]. Moreover, there is no improvement expected from employing acceptor materials based on conventional fullerene derivatives, mainly because of their limited contribution to light

*mesro@dtu.dk

${ }^{\dagger}$ These authors contributed equally to this work. absorption, the difficulty of tuning their energy levels, and their fast degradation under ambient conditions [10].

Nowadays, nonfullerene acceptors (NFAs) have attracted interest of the OSCs community mostly due to the possibility of altering their properties through molecular design, which allows for a precise tuning of their absorption spectrum, energy levels and stability [11-13]. During the last few years, the research on NFAs has skyrocketed the efficiency of OSCs, overcoming the $18 \%$ mark [14]. The small molecule $\left(5 Z, 5^{\prime} Z\right)-5,5^{\prime}-\left\{\left[7,7^{\prime}-(4,4\right.\right.$, 9,9-tetraoctyl-4,9-dihydro-s-indaceno[1,2- $\left.b: 5,6-b^{\prime}\right]$ dithiophene-2,7-diyl)bis(benzo[c][1,2,5]thiadiazole-7,4-diyl)]bis (methanylylidene)\}bis(3-ethyl-2-thioxothiazolidin-4-one) (O-IDTBR) is one of these recently developed NFAs [15-18]. Its molecular structure is shown in Fig. 1. In blends together with poly(3-hexylthiophene-2,5-diyl) (P3HT), small-scale spin-coated devices on ITO-coated glass have shown efficiencies close to 7\% [19]. P3HT is one of the most well-known electron-donor materials and has been widely used in combination with phenyl-C61(or 70)-butyric acid methyl ester (PCBM) in the last decades. Although the reported efficiencies for P3HT:PCBM are 


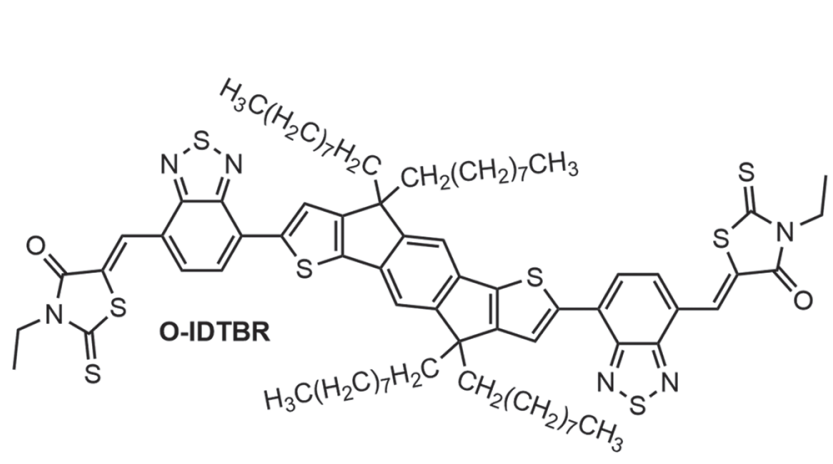

not impressive, $\mathrm{P} 3 \mathrm{HT}$ is still one the best-suited polymers for the large-scale fabrication of OSCs, due to its inexpensive and simple synthesis and its superior operation in thick active layers obtained when using scalable deposition techniques [20]. Recently, large-scale devices $\left(59.52 \mathrm{~cm}^{2}\right)$ were fabricated with this exact blend on ITO-coated glass substrates, achieving an impressive 5\% power conversion efficiency (PCE) [21]. Using ITO-free substrates, a $5.5 \%$ PCE was recently reported using a different material system, slot-die-coated on a sheet-to-sheet platform [22].

There have been no reports previously on P3HT:OIDTBR OSCs slot-die-coated on ITO-free flexible substrates fabricated on a roll-processing platform, which mimics large-scale full roll-to-roll processing. We strongly believe there is a need to enhance the performance of nonfullerene OSCs fabricated using scalable deposition techniques [22,23].

The so-called temperature-controlled slot-die coating (or hot slot-die coating), which consists of coating with a hot slot-die head, has demonstrated to be effective in increasing the photovoltaic (PV) performance of organic solar cells. It has been proven that matching the substrate and head temperatures yields the best performance possible, when it comes to active-layer coating of fullereneacceptor devices [24]. Additionally, it is suggested that matching temperatures in nonfullerene acceptor devices can have the same effect if the experimental conditions permit it [25].

An ideal electrode for solar cells should be ohmic, charge-carrier selective, and surface passivating [26-28]. Historically, the simplest way of inducing carrier selectivity for an electrode has been through the use of metals with different work functions. However, a metal electrode for OSCs with optimal properties might still need an interfacial layer of a different material [29], which can be metals, metal oxides (e.g., $\mathrm{MoO}_{x}$ ), or conductive polymers (e.g., PEDOT:PSS), to improve the carrier selectivity through modulation of the metal work function [30,31]. Here, we experiment with different thicknesses of the PEDOT:PSS layer prior to the deposition of $\mathrm{Ag}, \mathrm{Cu}$, and $\mathrm{Au}$ metal contacts. Several coating parameters are varied, with the
FIG. 1. Chemical structures of OIDTBR and P3HT. aim of finding the deposition conditions that lead to an optimal device performance. In the first section, the drum temperature (DT), the slot-die head temperature (HT), and thickness of the active layer are optimized. In the second part, we present the effect of diluting PEDOT:PSS with isopropanol (IPA). In the third part, we compare vacuum-deposited and open-air-printed electrodes. In the final experimental section, solar cells with different areas $\left(0.08-4 \mathrm{~cm}^{2}\right)$ are fabricated as a proof of concept of the scalability of our approach, with printed and evaporated Ag electrodes. We conclude that our devices printed in open air are suitable for large-scale production.

\section{EXPERIMENTAL SECTION}

\section{A. Materials}

All materials involved in this study are purchased and used without any further purification, unless mentioned otherwise. $\mathrm{P} 3 \mathrm{HT}$ is purchased from Ossila Materials (batch M1011, $\sim 60 \mathrm{kDa}$ ). O-IDTBR is purchased from 1-Material Inc. Dichlorobenzene (DCB), bromoanisole (BrA), IPA, and butanol are purchased from Sigma Aldrich Inc. PEDOT:PSS, for the hole-transport-layer study, is purchased from Heraeus (Heraeus CLEVIOS FET). The flexible substrate (flextrode) is produced at the Technical University of Denmark (DTU) [32]. It is composed of a polyethylene terephthalate (PET) substrate; a Ag grid (flexographic printing) as the top electrode; a layer of PEDOT:PSS (screen-printing); and, finally, a layer of $\mathrm{ZnO}$ nanoparticles as the electron-transport layer (slot-die coating) [33].

\section{B. Solar-cell fabrication}

The main piece of equipment used for the fabrication of fully roll-coated devices is an in-house-made roll coater, which is composed of a rotating drum and a slot-die coating head. This machine is compatible with roll-to-roll machines (Fig. 2). The full setup allows for the control of both temperature and speed of the drum, temperature of the head, drum-to-head distance, and ink flow rate. By simply attaching a rotating flexographic roll instead of a 


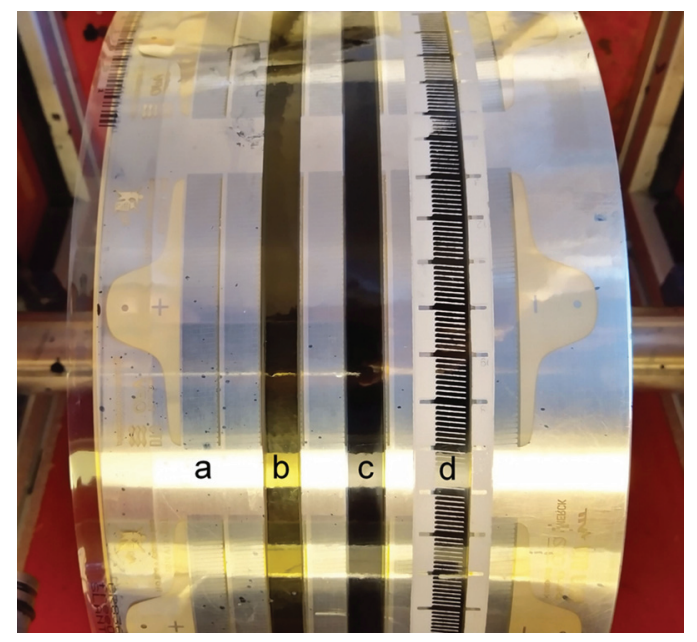

FIG. 2. In-house-made roll coater used to fabricate OSCs at DTU. Coating of the different layers, starting with the ITO-free flextrode substrate (a), the active layer of P3HT:PCBM (b), the PEDOT:PSS layer (c), and flexoprinted Ag fingers as the back contact (d).

coating head, flexographic printing is also possible with this equipment. The active-layer and hole-transport-layer coatings, as well as the flexographically printed silver back electrode, are fully done under ambient conditions (Fig. 2). Unless stated otherwise, a solution of P3HT:O-IDTBR with a concentration of $40 \mathrm{mg} / \mathrm{mL}$ in a $1: 1$ donor-toacceptor ratio is prepared in dichlorobenzene with $5 \%$ $(\mathrm{v} / \mathrm{v}) \mathrm{BrA}$ as an additive and magnetically stirred on a hot plate at $45^{\circ} \mathrm{C}$ for $15 \mathrm{~min}$. All devices in this work have an inverted architecture, namely, flextrode/P3HT:OIDTBR/PEDOT:PSS/back electrode (Ag-printed, Ag, $\mathrm{Cu}$, or $\mathrm{Au})$.

Flextrode $(1 \mathrm{~m})$ is fixed on the roll-coater drum; six different drum temperatures are tested for the drying of the active layer: room temperature (25), 40,60, 70, 80, and $90^{\circ} \mathrm{C}$. To study the impact of slot-die coating P3HT:OIDTBR at different temperatures, the slot-die head is heated to different temperatures $\left(25,40,60\right.$, and $\left.80^{\circ} \mathrm{C}\right)$, while keeping the drum at $60^{\circ} \mathrm{C}$. The temperature of the drum and slot-die head are independently controlled $\left( \pm 0.5^{\circ} \mathrm{C}\right)$.

The active layer is then slot-die-coated on the flextrode using a drum speed of $0.6 \mathrm{~m} / \mathrm{min}$ with a flow rate of $0.08 \mathrm{~mL} / \mathrm{min}$, resulting in a film with a dry thickness of $480 \mathrm{~nm}$, calculated by

$$
d=\frac{c f}{\rho v w}
$$

where $f$ corresponds to the ink flow rate; $w$ is the width of the film, in this case equal to $1 \mathrm{~cm}$; $v$ is the coating velocity; $c$ stands for the concentration of active layer materials (P3HT:O-IDTBR) per $\mathrm{mL}$ of solvent, in $\mathrm{mg} / \mathrm{mL}$; and $\rho$ is the density of the materials in bulk, set to $1.1 \mathrm{~g} / \mathrm{cm}^{3}$. The distance from the meniscus guide to the flextrode is set to approximately $2 \mathrm{~mm}$, always ensuring $w=1 \mathrm{~cm}$.

The flow rate is also modified to study the impact of the thickness on the performance and fixed to $0.06,0.10$, and $0.12 \mathrm{~mL} / \mathrm{min}$. These flow rates correspond to 360,600 , and $720 \mathrm{~nm}$, respectively, when introduced in (1). The procedures for subsequent layers remains the same. The active layer is surface treated using slot-die-coated butanol (drum: $1.2 \mathrm{~m} / \mathrm{min}, 70{ }^{\circ} \mathrm{C}$, head: $25^{\circ} \mathrm{C}, 0.25 \mathrm{~mL} / \mathrm{min}$ ) to allow PEDOT:PSS to stick to the surface of the bulk heterojunction. After sonication in a Hielscher UIP1000hdT homogenizer and filtering ( $1 \mu \mathrm{m}$ filter) of PEDOT:PSS, it is slot-die-coated on top of the active layer (drum: $1.25 \mathrm{~m} / \mathrm{min}, 70^{\circ} \mathrm{C}$, head: $25^{\circ} \mathrm{C}, 0.8 \mathrm{~mL} / \mathrm{min}$ ), resulting in a dry thickness on the micrometer order of magnitude. PEDOT:PSS is left to dry for $45 \mathrm{~min}$ on the drum at $70{ }^{\circ} \mathrm{C}$.

\section{Back-electrode modifications}

As our reference case, a heat-curing silver paste (DuPont 5025 ) is used to flexographically print the fingerlike back electrode [Fig. 2(d)] on top of the PEDOT:PSS layer (drum: $0.8 \mathrm{~m} / \mathrm{min}, 70^{\circ} \mathrm{C}$ ), giving a total area of $1 \mathrm{~cm}^{2}$. It is left to cure for $10 \mathrm{~min}$ at $70^{\circ} \mathrm{C}$ on the drum. Alternatively, $250 \mathrm{~nm}$ of $\mathrm{Ag}$ (99.99\%), $\mathrm{Au}$ (99.99\%), or $\mathrm{Cu}$

TABLE I. Maximum and average key parameters. PCE, (FF), $V_{\mathrm{OC}}$, and $J_{\mathrm{SC}}$ of encapsulated slot-die-coated solar cells on flexible ITO-free substrates with varying HT and DT.

\begin{tabular}{llcccc}
\hline \hline HT $\left({ }^{\circ} \mathrm{C}\right)$ & DT $\left({ }^{\circ} \mathrm{C}\right)$ & PCE $(\%)$ & FF $(\%)$ & $J_{\text {SC }\left(\mathrm{mA} / \mathrm{cm}^{2}\right)}$ \\
\hline 25 & 25 & $1.71(1.66 \pm 0.04)$ & $51.88(51.75 \pm 0.13)$ & $4.81(4.72 \pm 0.09)$ & $0.68(0.68 \pm 0.01)$ \\
25 & 50 & $2.59(2.59 \pm 0.01)$ & $61.80(60.68 \pm 1.12)$ & $6.02(6.07 \pm 0.05)$ & $0.70(0.70 \pm 0.01)$ \\
25 & 60 & $3.12(2.99 \pm 0.13)$ & $64.30(64.63 \pm 0.33)$ & $6.97(6.64 \pm 0.32)$ & $0.70(0.70 \pm 0.01)$ \\
25 & 70 & $3.07(2.99 \pm 0.08)$ & $62.39(63.00 \pm 0.61)$ & $6.89(6.69 \pm 0.20)$ & $0.71(0.71 \pm 0.01)$ \\
25 & 80 & $2.45(2.37 \pm 0.08)$ & $60.38(59.77 \pm 0.61)$ & $5.71(5.64 \pm 0.07)$ & $0.71(0.70 \pm 0.01)$ \\
25 & 90 & $2.21(2.17 \pm 0.04)$ & $56.05(52.70 \pm 3.35)$ & $5.63(5.85 \pm 0.22)$ & $0.70(0.71 \pm 0.01)$ \\
40 & 60 & $3.32(3.11 \pm 0.21)$ & $63.58(62.77 \pm 0.81)$ & $7.47(7.07 \pm 0.40)$ & $0.70(0.70 \pm 0.01)$ \\
60 & 60 & $3.45(3.26 \pm 0.14)$ & $60.48(62.49 \pm 0.42)$ & $7.94(7.41 \pm 0.38)$ & $0.72(0.71 \pm 0.01)$ \\
80 & 60 & $3.08(3.01 \pm 0.07)$ & $64.35(64.44 \pm 0.10)$ & $6.87(6.70 \pm 0.17)$ & $0.70(0.70 \pm 0.01)$ \\
\hline \hline
\end{tabular}


(99.9\%) from Sigma-Aldrich are thermally evaporated on top of the PEDOT:PSS layer through a shadow mask, giving an active area of $1 \mathrm{~cm}^{2}$. An INFICON XTM/2 system is used to monitor the deposition rate $(5 \AA / s)$ of the metals from tungsten boats with a base pressure of $1 \times 10^{-5}$ mbar. During the evaporation process, heating of the solar cells is negligible and these remain at ambient temperature.

\section{Hole-transport-layer study}

After slot-die coating a 480-nm-thick active layer (drum: $0.6 \mathrm{~m} / \mathrm{min}, 60^{\circ} \mathrm{C}$, head: $60^{\circ} \mathrm{C}, 0.08 \mathrm{~mL} / \mathrm{min}$ ), a solution made of diluted PEDOT:PSS in IPA in a ratio of $3: 1(\mathrm{v} / \mathrm{v})$ is coated using the following parameters, to achieve good covering films: head: $25^{\circ} \mathrm{C}, 0.30 \mathrm{~mL} / \mathrm{min}$; drum: $0.8 \mathrm{~m} / \mathrm{min}, 70^{\circ} \mathrm{C}$. Deposition of the thin film of PEDOT:PSS is followed by $250 \mathrm{~nm}$ evaporated Ag or flexoprinted Ag back electrodes.

\section{E. Activation and encapsulation}

A final step before encapsulation is necessary for working solar cells. After fabrication, the testing of the obtained layer stack results in a nonoperating device, showing a $J$ $V$ curve similar to that of a simple resistor. Activation of the final devices is done by applying a quick negative bias $(I=0.5 \mathrm{~A}$ and $V=20 \mathrm{~V})$ through the cell [34]. Encapsulation of the solar cells is achieved using a custom-made epoxy-based glue, EPXR, based on bisphenol A diglycidyl ether and Chissonox 221 monomers. The procedure consists of sandwiching the cell between two glass slides and applying the EPXR glue on both sides. Subsequently, the encapsulated solar cells are cured under UV light for $5 \mathrm{~min}$. A temperature of $(66 \pm 0.5){ }^{\circ} \mathrm{C}$ under the light is measured on the glass slides using a thermocouple.

\section{F. Characterization}

All current density-voltage $(J-V)$ curves are measured using a solar simulator with a xenon lamp as the light source, which is calibrated by a certified reference cell (monocrystalline silicon certified by Fraunhofer) under AM1.5G illumination, $1000 \mathrm{~W} / \mathrm{m}^{2}$ intensity, and acquired by a Keithley 2400 source meter $(25 \mathrm{mV}$ step reverse to forward). No current is obtained outside the solar-cell area, as the flextrode is cut to ensure $1 \mathrm{~cm}^{2}$ devices. The areas below $1 \mathrm{~cm}^{2}$ are obtained using shadow masks. The external quantum efficiency (QE) and absorbance are measured using a QEX10 system (PV Measurements Inc.) from 300 to $900 \mathrm{~nm}$ (5 nm step size) calibrated with a Si photodiode. The sheet resistance is measured with a four-point probe (Kulicke \& Soffa) acquired by a Keithley 2401 source meter. The morphology of the active layers is characterized with an AFM DS95-50 instrument from DME Danish Micro Engineering. The scans are carried out on $5 \times 5 \mu \mathrm{m}^{2}$ surface areas using noncontact mode.

\section{RESULTS AND DISCUSSION}

The morphology and crystalline-packing parameters of the active layer in OSCs have an important impact on the PV performance, because they affect exciton dissociation and charge transport inside the solar cells [35,36]. Morphology and crystallinity can be optimized by changing the drying kinetics of the organic films, through manipulation of the solvents or the temperature during deposition [37]. Our efforts towards optimizing the deposition of the P3HT:O-IDTBR active layer and the hole-transport layer using flexoprinted and evaporated electrodes are exposed in the following sections.

\section{A. Active-layer optimization}

Here, DCB-BrA (5\%) is used as the solvent combination. Other solvents are tested by choosing a wide range of boiling points (chloroform, chlorobenzene, and trichlorobenzene); none of them show a better performance than that of DCB (not shown here). BrA is chosen because of the promising results in our first tests, and in other publications, which suggest that this additive might be beneficial for the morphology of the blend [21]. The D-A ratio is also fixed at 1:1 after tests with representative ratios of 1.5:1 and 1:1.5, showing that the optimal PV parameters are achieved with a 1:1 blend (see supporting information Figure S1, Table S1); this is the ratio used in all subsequent experiments.

As expected from previously reported studies [24], we find that matching the slot-die head and drum temperatures at $60{ }^{\circ} \mathrm{C}$ leads to an optimal performance. The temperature used on the drum during active-layer coating is varied between $25^{\circ} \mathrm{C}$ and $90^{\circ} \mathrm{C}$. Figure $3(\mathrm{a})$, inset, shows the PCE evolution with the drum temperature for solar cells before (boxes) and after (dots) encapsulation for 30 and 15 devices, respectively. Each box encloses the first to the third quartile, where the median (horizontal line) and the mean (square) values are indicated. The epoxy-UV-curing process is similar to annealing. Annealing of the active layer is known to improve the crystallinity of the P3HT:OIDTBR active layer, enhancing charge transport, electron diffusion, and charge separation [15]. During this process, the temperature of the solar cell under the UV lamp reaches $(66 \pm 0.5)^{\circ} \mathrm{C}$, as measured with a K-type thermocouple touching the surface of the encapsulation glass directly exposed to the UV light. The PCE steadily improves when increasing the head temperarure from room temperature (around $25^{\circ} \mathrm{C}$ ) to $60^{\circ} \mathrm{C}$, reaching an average maximum value of $(2.99 \pm 0.13) \%$, which is higher than that of solar cells coated at $70^{\circ} \mathrm{C}$ (Table I). This value is the result of improved photocurrent from $(4.72 \pm 0.09) \mathrm{mA} / \mathrm{cm}^{2}$ at $25^{\circ} \mathrm{C}$ to $(6.64 \pm 0.32) \mathrm{mA} / \mathrm{cm}^{2}$ at $60^{\circ} \mathrm{C}$ and fill factor 
(a)

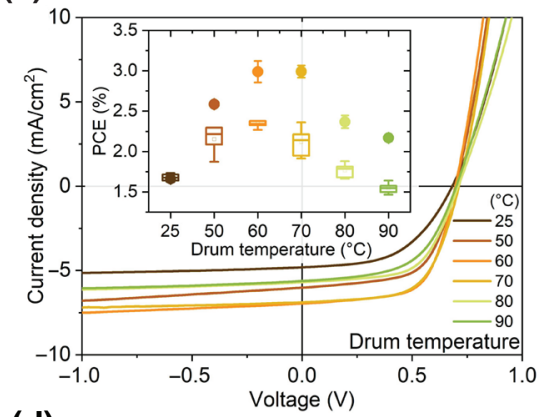

(d)

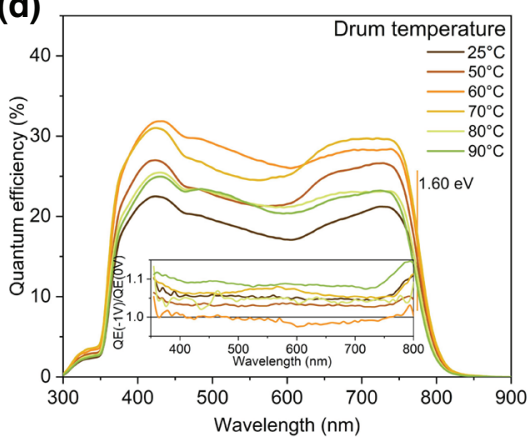

(b)

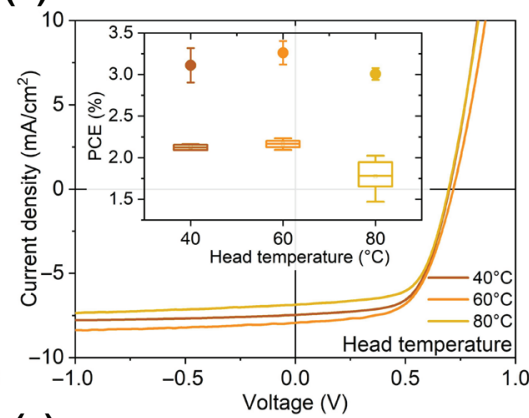

(e)

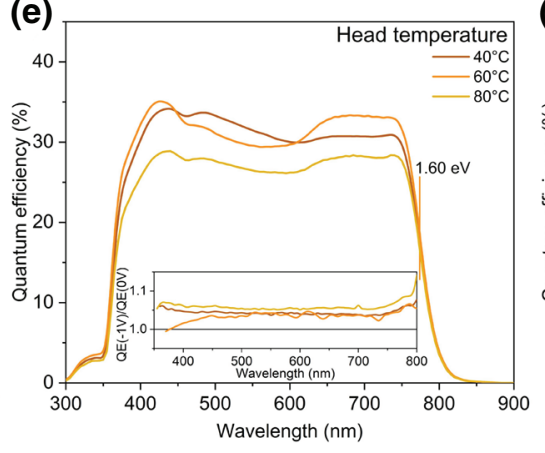

(c)

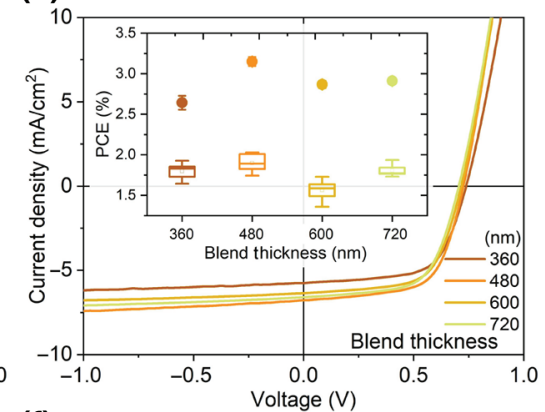

(f)

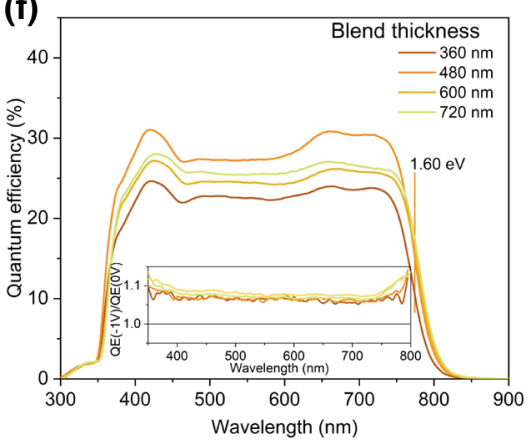

FIG. 3. Representative $J-V$ curves of encapsulated solar cells with (a) DT variations (with $\mathrm{HT}=25^{\circ} \mathrm{C}$ ), (b) $\mathrm{HT}$ variations (with $\mathrm{DT}=60^{\circ} \mathrm{C}$ ), and (c) thickness variations (DT $=\mathrm{HT}=60^{\circ} \mathrm{C}$ ). Insets in (a)-(c) show summary statistics of $J-V$ characteristics of solar cells before (boxes) and after (dots) encapsulation. External QE at $0 \mathrm{~V}$ bias of representative encapsulated solar cells from (d) DT variations, (e) HT variations, and (f) thickness variations. Insets in (d),(e) show the QE ratio at -1 and $0 \mathrm{~V}$ bias.

from $(51.75 \pm 0.13) \%$ at $25^{\circ} \mathrm{C}$ to $(64.63 \pm 0.33) \%$ at $60{ }^{\circ} \mathrm{C}$ (Appendix A, Drum temperature variations figure) for encapsulated devices. The QE curves [Fig. 3(d)] also follow this photocurrent gain trend. However, for these solar cells made with $\mathrm{HT}=$ room temperature $\left(25^{\circ} \mathrm{C}\right)$, the $\mathrm{QE}$ curves are clearly composed of two parts in the shortand long-wavelength regions. The combined photocurrent generation of the donor and acceptor is visible in the short-wavelength region, whereas the contribution of the acceptor has a maximum in the long-wavelength region. The QE bias ratio [Fig. 3(d), inset] shows that, from the spectral carrier collection viewpoint, $\mathrm{DT}=60^{\circ} \mathrm{C}$ is the optimum temperature, whereas DT $=90^{\circ} \mathrm{C}$ is the one that drifts the most from optimum. The DT/HT $=25^{\circ} \mathrm{C} / 25^{\circ} \mathrm{C}$ solar cell [Fig. 3(a)] has both a low short-circuit current density $\left(J_{\mathrm{SC}}\right)$ and low fill factor $(\mathrm{FF})$, as well as the lowest open-circuit voltage $\left(V_{\mathrm{OC}}\right)$. These differences automatically lead to a lower PCE $(1.66 \pm 0.04 \%)$, even after encapsulation (Figure S2).

The temperatures tested in the coating slot-die head are 40,60 , and $80^{\circ} \mathrm{C}$. These are chosen to have a range of temperatures centered on the optimal DT, both higher and lower. The limit is set to $80^{\circ} \mathrm{C}$ to avoid known problems in the head, such as an unstable meniscus during coating, i.e., due to the formation of bubbles in the solution. The solar cells obtained with $\mathrm{HT}=60^{\circ} \mathrm{C}$ (Table I) show a high average PCE $(3.26 \pm 0.14 \%)$. Going to lower or higher head temperatures reduces $J_{\mathrm{SC}}$, and hence, PCE (Figure S3). The spectral photocurrent collection improves when using a hot coating head, as shown in Fig. 3(e). In this case, the integrated QE photocurrents for $\mathrm{HT}=40,60$, and $80^{\circ} \mathrm{C}$ [Fig. 3(e)] are 7.87, 8.00, and $6.91 \mathrm{~mA} / \mathrm{cm}^{2}$, respectively, in agreement with their 1 sun $J-V$ curves from Table I. The optimal head temperature is then set to $60^{\circ} \mathrm{C}$.

As shown in Figs. 3(a)-3(c) and Table I, the coating parameter that affects the PV performance most is the DT (if $\mathrm{HT}=25^{\circ} \mathrm{C}$ ). The optimal combination of head and drum temperatures, in terms of PV parameters, corresponds to both being set at $60^{\circ} \mathrm{C}$, which is in accordance with the previously mentioned studies in different $\mathrm{D}$-A systems [24]. This combination of temperatures is an easy way to improve charge extraction from slot-die-coated OSCs via film morphology control and crystallinity. Ultimately, the combination of DT and HT improved the encapsulated devices by around $48 \% \mathrm{PCE}$ and $18 \% \mathrm{FF}$ compared with the $25^{\circ} \mathrm{C}$ and $25^{\circ} \mathrm{C}$ ones.

Subsequently, three additional thicknesses of P3HT:OIDTBR are tested with the optimal temperature combination, with values 360,600 , and $720 \mathrm{~nm}$ versus the previously deposited $480 \mathrm{~nm}$. This is done by keeping the speed of the drum constant, while increasing or reducing the ink flow rate accordingly. The results from this test are summarized in Figs. 3(c) and 3(f), which report the PCE, $J-V$, and $\mathrm{QE}$ curves obtained for each of the four thicknesses. 
Table S2 (Supporting Information) reports the average PV parameters obtained in this thickness study, where all PCEs are around 3\%. The best-performing cells correspond to those fabricated with a dry thickness of $480 \mathrm{~nm}$ (Figure S4) using a rate of only $0.08 \mathrm{~mL} / \mathrm{min}$, which allows $7.5 \mathrm{~m}$ of active layer to be coated per milliliter of active material.

AFM images are obtained from fresh slot-die-coated films to study the surface topography of the active-layer films. They are coated with different drum and head temperatures, as shown in Figs. 4(a)-4(c). The films show a surface topography composed of micron-sized grainlike structures with varying root-mean-square (rms) roughness. A flat bulk heterojunction topography induces a better interface with the PEDOT:PSS hole-transport layer (HTL), improving charge collection (Table I) [38,39]. The blend/HTL interface presented in Fig. 4 (showing the blend surface) exhibits significant differences between the surfaces of organic films coated at different head and drum temperatures. Figure 4(a) shows that the $25^{\circ} \mathrm{C} / 25^{\circ} \mathrm{C}$-coated film results in the highest surface roughness $(\mathrm{rms}=77 \mathrm{~nm})$. When the active layer is coated at DT $=60^{\circ} \mathrm{C}$, the bulk morphology of the active layer during roll coating might improve [40]; as a side effect, the film surface is smoother in terms of its rms $(28 \mathrm{~nm})$. A further surface roughness reduction is found when $60^{\circ} \mathrm{C}$ is used in both drum and coating head temperatures showing $\mathrm{rms}=25 \mathrm{~nm}$. Similar rms valueas are found in different areas of the films as shown in the supporting information Figure S5. In general, the changes observed in surface roughness may be a consequence of bulk morphology changes induced by the coating-temperature variations that influence the drying kinetics [41]. The hot drum and hot slot-die head induce highly ordered molecular packing [24], which improves carrier transport inside the bulk heterojunction $[24,25,42]$, improving $J_{\mathrm{SC}}$ and FF (Table I).

Modifications in the drum and head temperatures during coating also affect the optical properties of the films. Figure 4(d) shows the normalized absorbance of only donor, only acceptor, and P3HT:O-IDTBR blend films. The films are slot-die-coated on bare PET substrates, the effects of which are removed from the spectra. The measurement spots of the QE and absorbance are of the same size. The thicknesses of neat donor, neat acceptor, and blend films in Fig. 4(d) are 237, 242, and $240 \mathrm{~nm}$, respectively, which are thinner than the films used in the solar cells in this work, in order not to saturate the detector and be able to measure the possible absorbance variations in the ultraviolet-to-visible (UV-vis) spectral range. The longwavelength inflection point of the P3HT absorbance curve is at $1.99 \mathrm{eV}$, with strong absorbance in the visible region. The O-IDTBR absorbance curve has a long-wavelength inflection point at $1.71 \mathrm{eV}$, which is the same as that for the 1:1 blend, as expected. The inflection-point value indicates the point at which the absorbance is weak, i.e., radiation with longer wavelength can be harvested by other materials or technologies. The shaded area in Fig. 4(d) shows the absorbance enhancement of the blend when coated with the optimum parameters. A beneficial orientation effect of the acceptor might be induced when coating the active layer with a hot slot-die head (in this case at $60^{\circ} \mathrm{C}$ ), as the absorbance increases where the acceptor has absorption peaks. It might lead to efficient carrier transport [25], resulting in solar cells with better performance (Table I).

\section{B. Hole-transport-layer study}

To investigate the influence of diluting the PEDOT:PSS hole-transport layer with IPA, a dilution of PEDOT:PSS in IPA was prepared, in a ratio of IPA-to-PEDOT:PSS of $3: 1$. The possible advantages of diluting PEDOT:PSS with IPA are skipping the butanol surface-treatment step after active-layer coating (as IPA improves the wettability of the active layer), reducing the energy used to dry the HTL (because of a shorter drying time, as explained in the Sec. II), fabricating semitransparent solar cells, and reducing PEDOT:PSS consumption. (a)

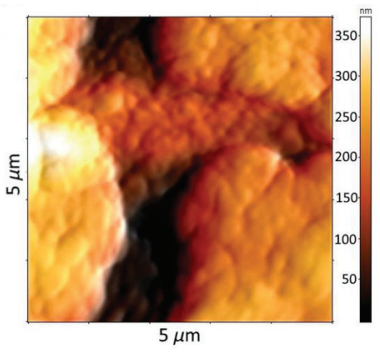

(b)

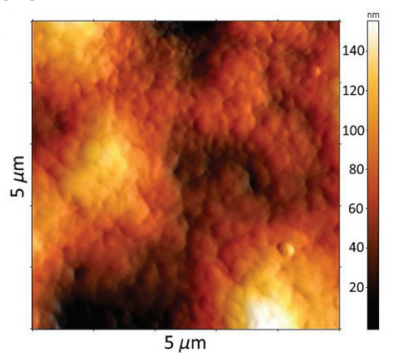

(c)

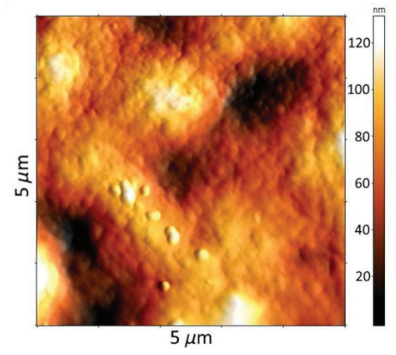

(d)

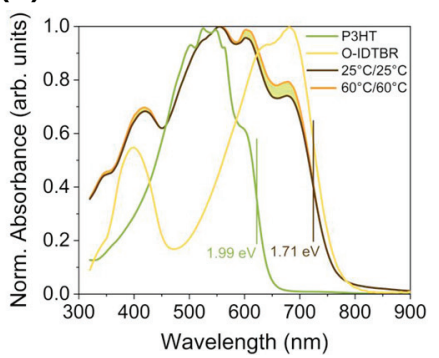

FIG. 4. AFM images (scan sizes $5 \times 5 \mu \mathrm{m}$ ) of P3HT:O-IDTBR blends $(1: 1)$ slot-die-coated in PET, with DT/HT $=(\mathrm{a}) 25^{\circ} \mathrm{C} / 25^{\circ} \mathrm{C}$, (b) $60^{\circ} \mathrm{C} / 25^{\circ} \mathrm{C}$, and (c) $60^{\circ} \mathrm{C} / 60^{\circ} \mathrm{C}$. (d) Normalized absorbance of as-deposited P3HT, O-IDTBR, and P3HT:O-IDTBR in 1:1 ratio with $\mathrm{DT} / \mathrm{HT}=25^{\circ} \mathrm{C} / 25^{\circ} \mathrm{C}, 60^{\circ} \mathrm{C}$. Vertical lines indicate the inflection point of the curves corresponding to their optical band gaps. 

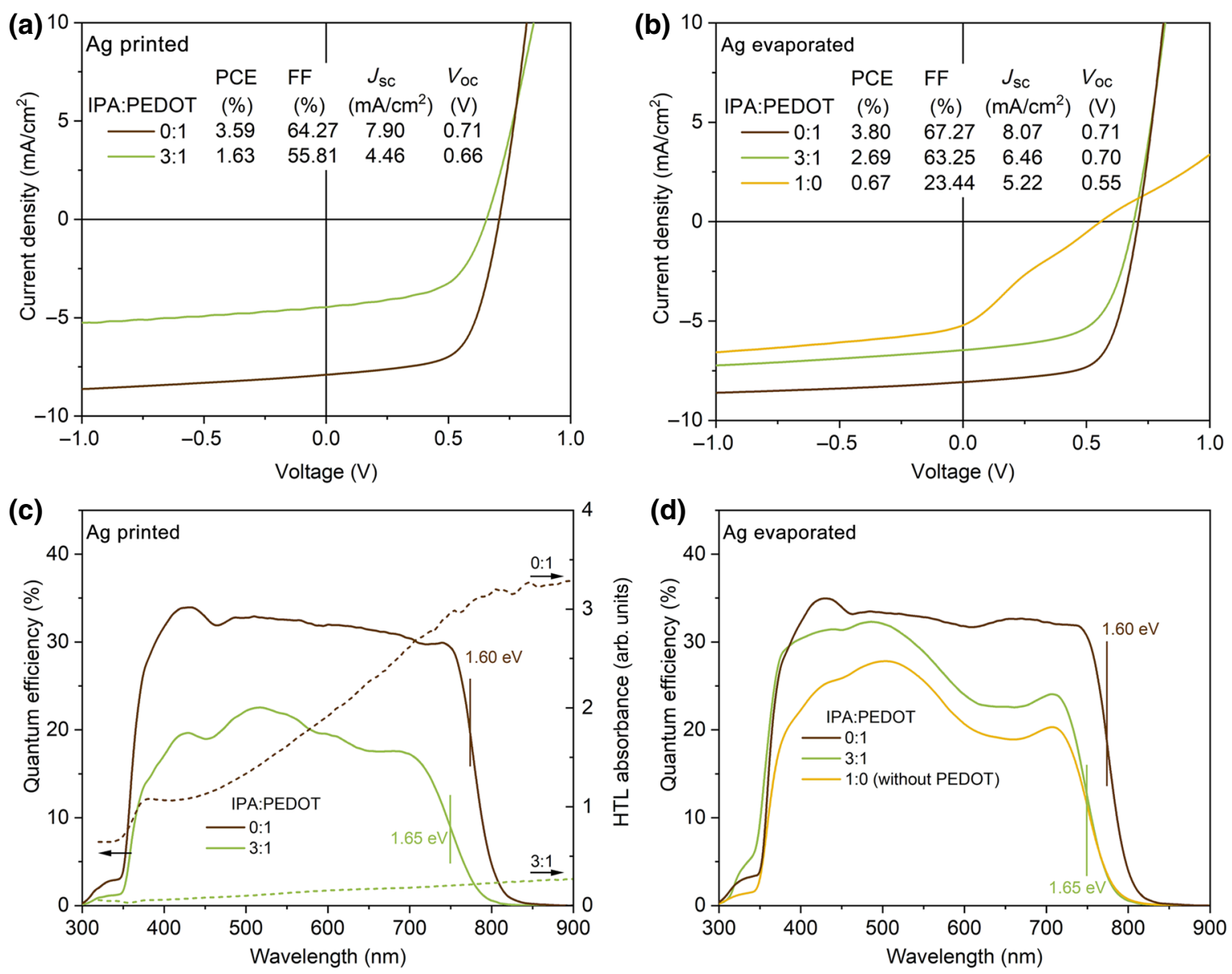

FIG. 5. Effect of diluting PEDOT:PSS HTL with IPA in OSCs with flexographically printed (a),(c) or thermally evaporated (b),(d) Ag back electrodes directly on top of the PEDOT:PSS layers. (a),(b) $J$ - $V$ curves of P3HT:O-IDTBR solar cells with IPA-diluted PEDOT:PSS layers; inset tables show the key photovoltaic parameters of the best-performing devices. (c),(d) Left axes show the external quantum efficiency of solar cells with printed or evaporated electrodes, respectively; vertical lines show the position of the photovoltaic band gap [49] of the devices. (c) Right axis shows absorbance of only PEDOT:PSS slot-die-coated films.

PEDOT:PSS layers are coated on top of the optimized $480 \mathrm{~nm}$ active layer, with both coating head and drum temperatures set at $60^{\circ} \mathrm{C}$. It is important to mention that IPA in the 3:1 solution is enough to make the PEDOT:PSS stick without butanol surface treatment of the active layer. A smaller amount of IPA leads to a lower chance of adhesion between PEDOT:PSS and the active layer due to the poor wettability of the active layer by PEDOT:PSS.

With the intention of comparing the performance of these devices produced by diluting PEDOT:PSS with IPA, a new batch of solar cells with pure PEDOT:PSS is also made. We encounter difficulties when printing the silver top electrode on the diluted PEDOT:PSS layers, as they are too thin to resist the flexoprinting procedure. Indeed, many of the resulting printed silver cells perform poorly. Before encapsulation, the printed silver cells with a $3: 1$ ratio exhibit an S-shaped $J$ - $V$ curve (Figure 6) under illumination. It is reported to be caused by mechanisms affecting the extraction of electrons near the device cathode $[28,43]$, in some cases, because of changes in the device architecture [28]. In our case, one possible reason could be the lack of a butanol surface-treatment step. Nevertheless, the $J-V$ curves of the solar cells with an evaporated silver back electrode do not show S-shaped $J-V$ curves before encapsulation. One hypothesis is that it could be due to the desorption of molecular oxygen [44]. Adsorbed oxygen could act as a trap state; in our case, oxygen desorption is induced by the vacuum step. The readsorption process is kinetically slow [45,46], allowing for switching and encapsulation of the devices in a few minutes. An additional possibility is light activation of the $\mathrm{ZnO}$ layer, which fills electron traps in the $\mathrm{ZnO}$ layer upon UV exposure [47], increasing its conductivity. This is in agreement with our results, as UV light is reported to improve the organic photovoltaic performance, correct the $\mathrm{S}$ shape, and promote favorable redistribution of oxygen in encapsulated OSCs [48]. 
After process optimization, encapsulated solar cells with nondiluted PEDOT:PSS show a PCE of 3.59\% [Fig. 5(a)], obtained in a full open-air process, whereas a slightly higher PCE of $3.8 \%$ is measured in a device with evaporated Ag back electrode [Fig. 5(b)]. The average PCEs of this set of samples are $(3.44 \pm 0.14) \%$ and $(3.64 \pm 0.12) \%$, respectively (see Table S3). The higher FF and $J_{\mathrm{SC}}$ values of the solar cells with Ag evaporated back electrodes are, in part, responsible for the higher PCE.

The $J-V$ characteristics of solar cells with diluted PEDOT:PSS show a decline in performance for both printed [Fig. 5(a)] and evaporated [Fig. 5(b)] Ag electrodes, mainly because of a decrease in the collected photocurrent. In the solar cells used to obtain the results reported in Fig. 5, PEDOT:PSS diluted with IPA and pure PEDOT:PSS cover the desired area of the active layer, resulting in solar cells with the same active area. On average, an encapsulated solar cell with printed $\mathrm{Ag}$ electrodes with nondiluted PEDOT:PSS produces $(3.38 \pm 0.24) \mathrm{mA} / \mathrm{cm}^{2}$ more than a solar cell with diluted PEDOT:PSS 3:1. The $J-V$ curve of a solar cell without PEDOT:PSS is shown in Fig. 5(b), where a very poor performance is obtained due to the absence of a HTL layer that could impede recombination of the generated carriers in forward bias.

The absorbance of the PEDOT:PSS HTL slot-diecoated on bare PET foil is shown in Fig. 5(c), with the contribution of the PET substrate removed. It shows a broad absorption over the full spectral range for both films, where the reduction in thickness resulting from diluting PEDOT:PSS with IPA is evidenced by an optically thinner film with lower absorption. The QE curves [Figs. 5(c) and 5(d)] of the devices with diluted PEDOT:PSS show an overall decrease, with respect to the QE curves of the solar cells with nondiluted PEDOT:PSS. For the case of Ag printed electrodes [Fig. 5(c)], the integrated QE currents are 8.03 and $4.49 \mathrm{~mA} / \mathrm{cm}^{2}$ (Table S4) for pure and diluted PEDOT:PSS, respectively, which are in agreement with their 1 sun $J-V$ curves. For the solar cells with evaporated electrodes on top of IPA-to-PEDOT:PSS layers in ratios $0: 1,3: 1$, and $1: 0$, the $\mathrm{QE}$ integrated currents are $8.24,6.33$, and $5.28 \mathrm{~mA} / \mathrm{cm}^{2}$ (Table S4), respectively, in agreement with their 1 sun $J$ - $V$ curves.

The PV parameter that is affected most when using a HTL diluted with IPA is the $J_{\mathrm{SC}}$. There are many possible reasons that may explain the lower current density of the devices with diluted PEDOT:PSS. Given that the $V_{\mathrm{OC}}$ and FF values remain almost the same, this effect could be due to alterations of the blend morphology produced by penetration of IPA into the active layer during the drying step at $70^{\circ} \mathrm{C}$. Another hypothesis is that IPA dissolves some of the acceptor at the interface (with subsequent mixing with PEDOT:PSS), causing a different interface composition compared with that of devices where IPA is not used. An alternative scenario could be the diffusion of some component of the IPA:PEDOT dilution into the active layer, doping it, and creating charge traps, thereby reducing the current and modifying the band gap of the active layer. A thorough explanation of the changes in the optoelectronic characteristic of devices with diluted PEDOT:PSS is beyond the scope of this publication. The hypotheses proposed here may not be exhaustive.

\section{Back-electrode modifications}

In the inverted configuration of OSCs, the back electrode is the last part of the device to be prepared. In this section, we present a direct comparison of different back electrodes viewed only as a channel for the generated carriers to an external circuit. As described in Sec. II, we compare two deposition techniques for the back electrode: flexographic printing (Fig. 2) and thermal evaporation. Different materials are employed as electrodes, both printed silver fingers and evaporated silver, evaporated copper, and evaporated gold, which are tested in two to four batches of solar cells with a total area of $1 \mathrm{~cm}^{2}$.

By employing different back electrodes, we experimentally examine if a less-expensive metal, such as copper, could improve the solar-cell performance, as well as if, conversely, it would be worthwhile to use a more
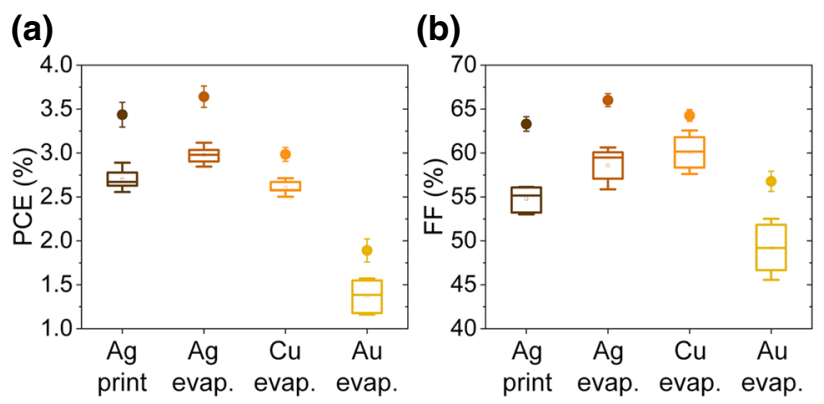

(c)

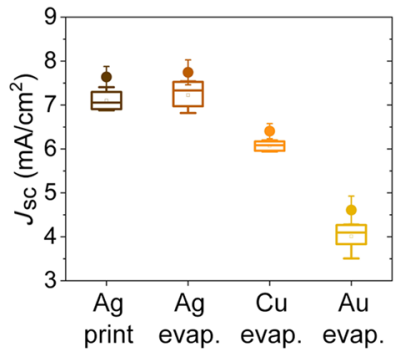

(d)

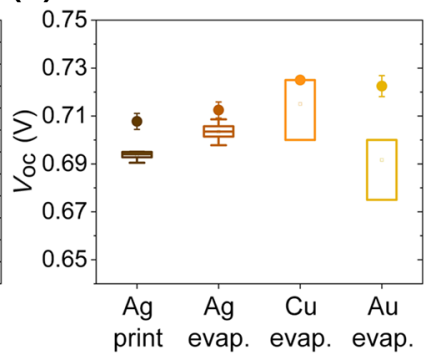

FIG. 6. Summary of key PV parameters of P3HT:O-IDTBR solar cells with different back electrodes, before (boxes) and after (dots) encapsulation for (a) power conversion efficiency, (b) fill factor, (c) current density, and (c) open-circuit voltage. 
TABLE II. Photovoltaic characteristics [50] of organic solar cells with printed back electrodes. Areas below $1 \mathrm{~cm}^{2}$ are obtained using shadow masks; the shadow area of the silver fingers from the flextrode is not subtracted (aperture area) [54].

\begin{tabular}{ccccccccc}
\hline \hline & Area $\left(\mathrm{cm}^{2}\right)$ & PCE $(\%)$ & FF $(\%)$ & $J_{\text {SC }}\left(\mathrm{mA} / \mathrm{cm}^{2}\right)$ & $V_{\mathrm{OC}}(\mathrm{V})$ & $R_{s}\left(\Omega \mathrm{cm}^{2}\right)$ & $R_{\text {sh }}\left(\mathrm{k} \Omega \mathrm{cm}^{2}\right)$ & Max. power $(\mathrm{mW})$ \\
\hline Ag printed & 4.00 & 2.31 & 54.04 & 5.84 & 0.733 & 21.80 & 1.00 & 9.26 \\
& 0.70 & 3.50 & 64.83 & 7.69 & 0.703 & 4.91 & 1.59 & 2.45 \\
& 0.25 & 3.58 & 67.25 & 7.90 & 0.674 & 1.86 & 1.27 & 0.90 \\
& 0.20 & 3.38 & 67.36 & 7.55 & 0.665 & 1.50 & 1.25 & 0.68 \\
& 0.08 & 2.98 & 62.59 & 7.55 & 0.632 & 0.59 & 0.75 & 0.24 \\
\hline \hline
\end{tabular}

expensive non-air-sensitive metal, such as gold. After evaporation of the back contacts, all solar cells are exposed to air for a few minutes for switching before encapsulation. As a first step, the sheet resistance of all four materials is measured on bare PET foil (Figure S7). The Ag front electron-collecting electrode on the flextrode is also measured. The lowest values are measured for evaporated silver on PET $0.277 \pm 0.007 \Omega /$ sq, closely followed by silver on the flextrode $0.329 \pm 0.005 \Omega /$ sq. Copper and gold have sheet resistance values of $0.587 \pm 0.007$ and $0.589 \pm 0.007 \Omega /$ sq, respectively. The highest sheet resistance is measured for printed silver, $2.26 \pm 0.08 \Omega / \mathrm{sq}$, which turns out to be practically as good as that of evaporated silver, in terms of PCE. It should be noted that these sheet-resistance values might differ from those of the electrodes on the actual solar cells after encapsulation and the epoxy-UV-curing process.

The $J-V$ and Qe curves of representative solar cells with the different electrodes from this section are shown in Figure S8. The solar cells with $\mathrm{Cu}$ electrodes show a very high tolerance to the switching current needed to activate the cells before characterization under the solar simulator. The electrode does not show any trace of damage, even when enduring repeated high currents $(600 \mathrm{~mA}, 2 \mathrm{~s})$. However, more effort is needed to obtain working devices compared with the evaporated or printed silver cells. The solar cells with $\mathrm{Cu}$ electrodes show an average (see Table S5) PCE and FF of $2.98 \pm 0.08 \%$ and $64.27 \pm 0.66 \%$, respectively; these values are both lower than those in the devices with evaporated or printed $\mathrm{Ag}$. The low $J_{\mathrm{SC}}$ of the solar cells with the $\mathrm{Cu}$ electrode $\left(1.5 \mathrm{~mA} / \mathrm{cm}^{2}\right.$ lower than that of the evaporated $\mathrm{Ag}$ counterpart) is the main reason for the low PCE. The QE of a solar cell with a Cu back electrode, shows low values over the entire spectral range, implying a smaller integrated $J_{\mathrm{SC}}\left(6.53 \mathrm{~mA} / \mathrm{cm}^{2}\right.$, see Table S5), in agreement with its 1 sun $J_{\mathrm{SC}}$ value.

The cells with $\mathrm{Au}$ electrodes are especially difficult to switch, as the electrode cannot tolerate a small reverse bias current as easily as that of $\mathrm{Cu}$ or Ag. The solar cells with Au electrodes perform very poorly compared with the rest, as can be seen from their PCE, FF, and $J_{\mathrm{SC}}$ values in Fig. 6. The $J_{\mathrm{SC}}$ of the solar cells with Au electrodes is especially low, with an average value (see Table S5) of $4.61 \pm 0.32 \mathrm{~mA} / \mathrm{cm}^{2}$, which suggests that Au alone on top of PEDOT:PSS is a less-efficient electrode than that of $\mathrm{Ag}$. The series resistance $\left(R_{S}\right)$, shunt resistance $\left(R_{\mathrm{sh}}\right)$, and recombination current density $\left(J_{0}\right)$ for the solar cells with different back electrodes are reported in supporting information Table S6, where the solar cell with the $\mathrm{Au}$ electrode has the highest $R_{S}$ of $12.7 \Omega \mathrm{cm}^{2}$ and the solar cell with the evaporated $\mathrm{Ag}$ back electrode has a lower $J_{0}$ value of $0.2 \mu \mathrm{A} / \mathrm{cm}^{2}$ in the dark.

Some of the optical losses are illustrated in Figure S8(b), where the transmittance of glass and glass/epoxy is presented. The front glass used for encapsulation transmits only $95 \%$ of the incoming light for $\lambda>350 \mathrm{~nm}$. After encapsulation, the optical window glass/epoxy transmits light only for $\lambda>363 \mathrm{~nm}$, reaching $94 \%$ transmittance only for $\lambda>550 \mathrm{~nm}$. This opens up the possibility for future optical improvements.

Figure 6 shows the key PV parameters of $1 \mathrm{~cm}^{2}$ solar cells with the electrode materials used in this section, for 24 solar cells before (boxes) and after (dots) encapsulation. The wide spread of values before encapsulation reveals the difficulties in switching, and after encapsulation some of the solar cells with $\mathrm{Cu}$ or $\mathrm{Au}$ electrodes even stop working. Despite $\mathrm{Cu}$ and $\mathrm{Au}$ being good electrical conductors, with low sheet resistance, these results show that these are necessary, but not sufficient, conditions to form a good electrode. One possibility for the enhanced photocurrent of the solar cells with Ag evaporated electrodes could be that $\mathrm{Ag}$ reflects more light than that of $\mathrm{Cu}$ or $\mathrm{Au}$. However, the front total reflectance of the OSCs (the reflectance measured on the PET side of the solar cells) with $\mathrm{Ag}$ and $\mathrm{Cu}$ electrodes is very similar in both devices, around $6 \%$ over the entire spectral range (see Figure S9). Reflected light is possibly absorbed by the PEDOT:PSS and active layer before it leaves the solar cell, which makes both devices reflect almost the same amount of light. Despite some obvious differences in photocurrent for each contact, the reason behind them is unclear and a trend cannot be found, meaning that further investigation is needed. Possible reasons for their low photocurrent could be that switching does not activate the full area, leaving inactive areas in the solar cell. An additional reason could be that evaporated $\mathrm{Cu}$ and $\mathrm{Au}$ metals penetrate into the 
PEDOT:PSS layer [52,53], causing a performance drop. A thin layer of transition-metal oxide (i.e., $\mathrm{MoO}_{x}$ ) can help slow the diffusion of metals, passivate the back interface, and improve the hole selectivity of the electrode. If diffusion of metals takes place, it does not reach the active layer, as the $V_{\mathrm{OC}}[50,51]$ and $E_{g}^{\mathrm{PV}}$ of the solar cells is similar for all, with $\Delta V_{\mathrm{OC}}^{\mathrm{PV}}$, in all cases, in the order of $0.8 \mathrm{~V}$ (see Table S4 and Table S5). It is important to mention that other phenomena could be responsible for such discrepancies in performance when using $\mathrm{Cu}$ and $\mathrm{Au}$ contacts. In fact, the small difference in sheet resistance between $\mathrm{Cu}$ and $\mathrm{Ag}$ is unlikely to explain such a large drop in $J_{\mathrm{SC}}$. Likewise, the small work-function difference between $\mathrm{Au}$ and Ag is unlikely to justify such a loss of performance.

Figure 7(a) clearly shows that the optimal electrode materials are those used in the previous section: printed and thermally evaporated silver, with maximum PCEs of $3.59 \%$ and $3.80 \%$, respectively. These results are especially important for considering a manufacturing trade-off. In fact, flexographic printing does not require any added vacuum steps in the process, yet still yields efficiencies that are comparable to those of evaporated silver.

\section{Different area devices}

As a proof of the scalability of our approach, larger area devices are also fabricated to study the evolution of photovoltaic performance when upscaling. The exact same experimental procedure is followed. The printed cells are cut into larger areas by simply not separating individual cells, creating solar cells with total areas of up to $4 \mathrm{~cm}^{2}$ [Fig. 7(a)]. The maximum PCE measured in this case is $2.31 \%$, with a $\mathrm{FF}$ of $54 \%$, and a maximum short-circuit current of $23.39 \mathrm{~mA}$, achieving a maximum power point of $9.26 \mathrm{~mW}$ [Fig. 7(c), Table II]. The $4 \mathrm{~cm}^{2}$ solar cell with printed electrodes shows a decrease in PCE of around 35\% when compared with the maximum PCE demonstrated by the $1 \mathrm{~cm}^{2}$ cells. A component of the loss can be associated with the decrease in $\mathrm{FF}$, which correlates with the extremely high $R_{S}=21.8 \Omega \mathrm{cm}^{2}$, which increases by one order of magnitude with respect to the $1 \mathrm{~cm}^{2}$ device. The evolution of $R_{S}$ with the area of the solar cells is presented in Fig. 7(b). $R_{S}$ is one of the challenges of upscaling, as it includes the influence of the electrodes and different layers in the solar cell; optimization of the process and materials should provide a value of $R_{S}$ that is as low as possible. One way to reduce it is to use full-area electrodes, as in the case of the evaporated Ag electrodes (See Figure 7(b) and Table $\mathrm{S} 7$ ), where $R_{S}$ is systematically low. Full-area electrodes help to compensate for the small diffusion length of some photoactive materials [55]. However, they can increase the probability of carrier recombination for nonpassivated electrodes [56]. The significantly lower $J_{\mathrm{SC}}$ value of the $>1 \mathrm{~cm}^{2}$ solar cell cannot be explained
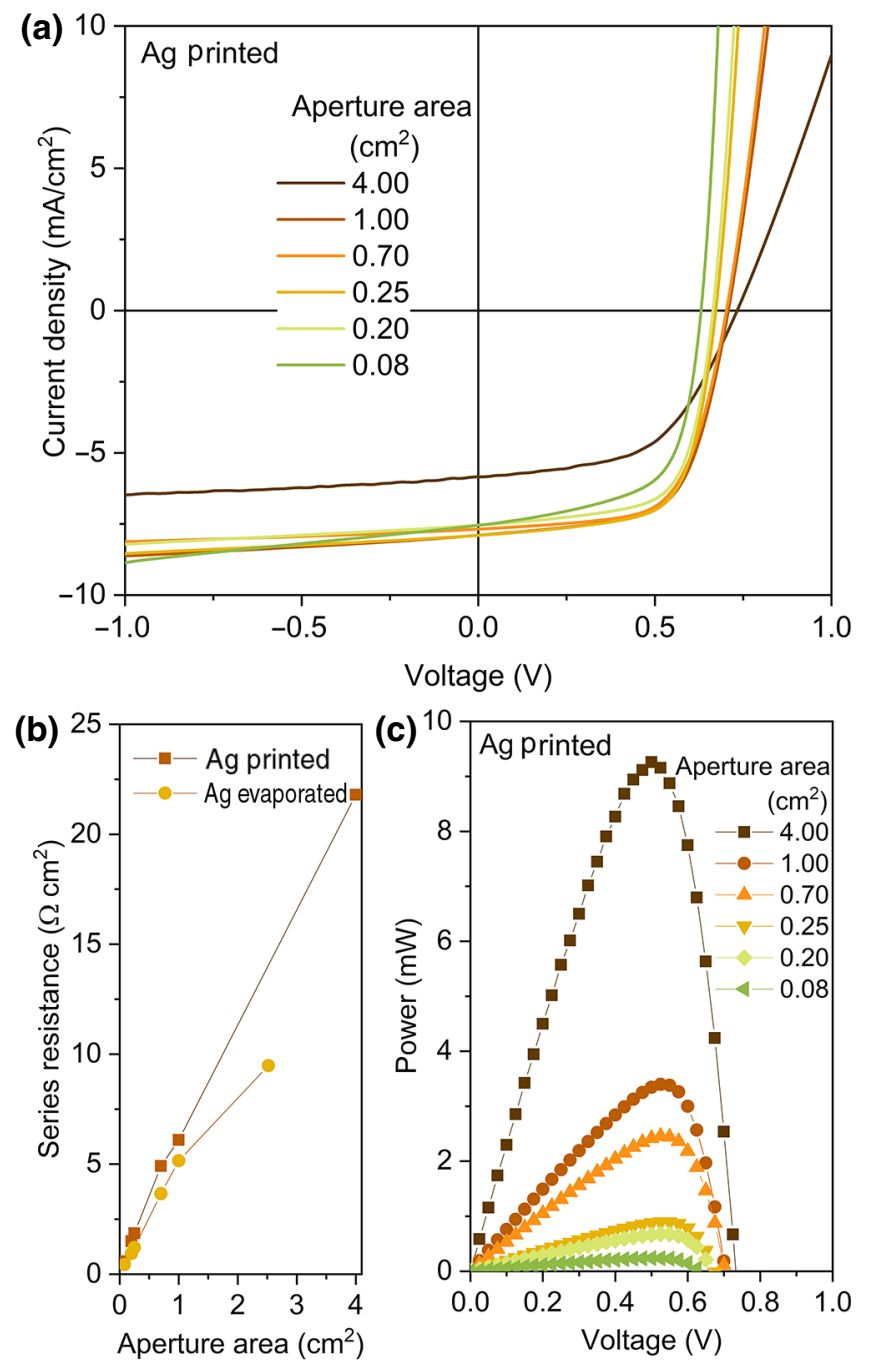

FIG. 7. (a) $J-V$ curves of solar cells with different active areas using printed $\mathrm{Ag}$ back electrodes. Areas below $1 \mathrm{~cm}^{2}$ are obtained using shadow masks on the $1 \mathrm{~cm}^{2}$ cell. (b) Series resistance $\left(R_{\mathrm{s}}\right)$ of solar cells with flexoprinted (squares) and evaporated (circles) Ag back electrodes. (c) Electrical power delivered by solar cells with flexoprinted $\mathrm{Ag}$ back electrodes and different aperture areas.

solely by the increase in $R_{S}$ (see Table 7 supporting information [57]), which means that alternative mechanisms are playing a role in decreasing the performance of that device. A feasible explanation for this could be the presence of inhomogeneities in the active layer, disconnected areas, nonswitched areas, or shadowing from the Ag fingers in the flextrode that cause an effectively smaller active area of the device, resulting in a lower short-circuit current. At this point, the introduction of vacuum steps into the process does not show a clear advantage, and consequently, open-air-produced OSCs are more suitable for upscaling. Additional experimental results can be found in the Supplementary information [58]. 


\section{CONCLUSIONS}

An optimization approach for the scalable fabrication of fullerene-free OSCs based on P3HT:O-IDTBR is developed using roll processing on flexible and ITO-free substrates. The optimization method is based on independently modifying several coating parameters, which are known to affect the photovoltaic performance of organic solar cells. The substrate temperature, the slot-die head temperature, the thickness of the active layer, the holetransport layer, and the back electrode are studied and optimized.

By optimizing the processing conditions, power conversion efficiencies as high as $3.59 \%$ are achieved for $1 \mathrm{~cm}^{2}$ solar cells, which are fabricated fully under ambient conditions. This is the state-of-the-art efficiency for this active-layer system using ITO-free flexible substrates on an open-air roll-processing platform. The efficiency is improved up to $3.8 \%$ PCE when evaporated silver is used as a back electrode. Improving the current density is the main challenge of the solar cells presented herein.

We strongly believe that our results can be used as a general approach for the optimization of nonfullerene organic solar cells fabricated by slot-die coating. Our findings also show that further attention to intermediate steps in the fabrication of devices is necessary, as crucial steps are not usually described and can severely affect the overall performance of the final devices.

In addition, this work clearly confirms P3HT:O-IDTBR as a suitable candidate for the large-scale fabrication of organic solar cells and, therefore, for the possible commercialization of the technology.

\section{ACKNOWLEDGMENTS}

We gratefully acknowledge funding from the European Research Council (ERC) under the European Union's Horizon 2020 research and innovation programme (SEEWHI Solar Energy Enabled for the World by High Resolution Imaging, Grant No. 681881). We thank Kristian Larsen for technical help during the production of the solar cells.

The authors declare no conflicts of interest.

[1] N. Espinosa, M. Hösel, D. Angmo, and F. C. Krebs, Solar cells with one-day energy payback for the factories of the future, Energy Environ. Sci. 5, 5117 (2012).

[2] B. Azzopardi, C. J. M. Emmott, A. Urbina, F. C. Krebs, J. Mutale, and J. Nelson, Economic assessment of solar electricity production from organic-based photovoltaic modules in a domestic environment, Energy Environ. Sci. 4, 3741 (2011).

[3] H. Cha, S. Wheeler, S. Holliday, S. D. Dimitrov, A. Wadsworth, H. H. Lee, D. Baran, I. McCulloch, and J.
R. Durrant, Influence of blend morphology and energetics on charge separation and recombination dynamics in organic solar cells incorporating a nonfullerene acceptor, Adv. Funct. Mater. 28, 1704389 (2018).

[4] L. Zhang, B. Lin, B. Hu, X. Xu, and W. Ma, Blade-Cast nonfullerene organic solar cells in Air with excellent morphology, efficiency, and stability, Adv. Mater. 30, 1800343 (2018).

[5] L. Ye, Y. Xiong, Q. Zhang, S. Li, C. Wang, Z. Jiang, J. Hou, W. You, and H. Ade, Surpassing 10\% efficiency benchmark for nonfullerene organic solar cells by scalable coating in Air from single nonhalogenated solvent, Adv. Mater. 30, 1705485 (2018).

[6] L. Ye, Y. Xiong, H. Yao, A. Gadisa, H. Zhang, S. Li, M. Ghasemi, N. Balar, A. Hunt, B. T. O'Connor, J. Hou, and H. Ade, High performance organic solar cells processed by blade coating in Air from a benign food additive solution, Chem. Mater. 28, 7451 (2016).

[7] X. Gu, Y. Zhou, K. Gu, T. Kurosawa, Y. Guo, Y. Li, H. Lin, B. C. Schroeder, H. Yan, F. Molina-Lopez, C. J. Tassone, C. Wang, S. C. B. Mannsfeld, H. Yan, D. Zhao, M. F. Toney, and Z. Bao, Roll-to-Roll printed large-area Allpolymer solar cells with $5 \%$ efficiency based on a Low crystallinity conjugated polymer blend, Adv. Energy Mater. 7, 1602742 (2017)

[8] B. Lin, L. Zhang, H. Zhao, X. Xu, K. Zhou, S. Zhang, L. Gou, B. Fan, L. Zhang, H. Yan, X. D. Gu, L. Ying, F. Huang, Y. Cao, and W. Ma, Molecular packing control enables excellent performance and mechanical property of blade-cast all-polymer solar cells, Nano Energy 59, 277 (2019).

[9] R. Ganesamoorthy, G. Sathiyan, and P. Sakthivel, Review: Fullerene based acceptors for efficient bulk heterojunction organic solar cell applications, Sol. Energy Mater. Sol. Cells 161, 102 (2017).

[10] A. Distler, T. Sauermann, H. J. Egelhaaf, S. Rodman, D. Waller, K. S. Cheon, M. Lee, and D. M. Guldi, The effect of PCBM dimerization on the performance of bulk heterojunction solar cells, Adv. Energy Mater. 4, 1300693 (2014).

[11] A. Venkateswararao, S. W. Liu, and K. T. Wong, Organic polymeric and small molecular electron acceptors for organic solar cells, Mater. Sci. Eng. R Reports 124, 1 (2018).

[12] C. Yan, S. Barlow, Z. Wang, H. Yan, A. K. Y. Jen, S. R. Marder, and X. Zhan, Non-fullerene acceptors for organic solar cells, Nat. Rev. Mater. 3, 18003 (2018).

[13] J. Hou, O. Inganäs, R. H. Friend, and F. Gao, Organic solar cells based on non-fullerene acceptors, Nat. Mater. 17, 119 (2018).

[14] Q. Liu, Y. Jiang, K. Jin, J. Qin, J. Xu, W. Li, J. Xiong, J. Liu, Z. Xiao, K. Sun, S. Yang, X. Zhang, and L. Ding, 18\% efficiency organic solar cells, Sci. Bull. 6, 16 (2020).

[15] S. Holliday, R. S. Ashraf, A. Wadsworth, D. Baran, S. A. Yousaf, C. B. Nielsen, C. H. Tan, S. D. Dimitrov, Z. Shang, N. Gasparini, M. Alamoudi, F. Laquai, C. J. Brabec, A. Salleo, J. R. Durrant, and I. McCulloch, High-efficiency and air-stable P3HT-based polymer solar cells with a new non-fullerene acceptor, Nat. Commun. 7, 11585 (2016).

[16] A. Wadsworth, Z. Hamid, M. Bidwell, R. S. Ashraf, J. I. Khan, D. H. Anjum, C. Cendra, J. Yan, E. Rezasoltani, 
A. A. Y. Guilbert, M. Azzouzi, N. Gasparini, J. H. Bannock, D. Baran, H. Wu, J. C. de Mello, C. J. Brabec, A. Salleo, J. Nelson, et al., Progress in poly (3-hexylthiophene) organic solar cells and the influence of Its molecular weight on device performance, Adv. Energy Mater. 8, 1801001 (2018).

[17] S. F. Hoefler, T. Rath, N. Pastukhova, E. Pavlica, D. Scheunemann, S. Wilken, B. Kunert, R. Resel, M. Hobisch, S. Xiao, G. Bratina, and G. Trimmel, The effect of polymer molecular weight on the performance of PTB7-Th:O-IDTBR non-fullerene organic solar cells, J. Mater. Chem. A 6, 9506 (2018).

[18] S. Chen, Y. Wang, L. Zhang, J. Zhao, Y. Chen, D. Zhu, H. Yao, G. Zhang, W. Ma, R. H. Friend, P. C. Y. Chow, F. Gao, and H. Yan, Efficient nonfullerene organic solar cells with small driving forces for both hole and electron transfer, Adv. Mater. 30, 1804215 (2018).

[19] J. I. Khan, R. S. Ashraf, M. A. Alamoudi, M. N. Nabi, H. N. Mohammed, A. Wadsworth, Y. Firdaus, W. Zhang, T. D. Anthopoulos, I. McCulloch, and F. Laquai, P3HT molecular weight determines the performance of P3HT:O-IDTBR solar cells, Sol. RRL 3, 1900023 (2019).

[20] M. Jørgensen, K. Norrman, S. A. Gevorgyan, T. Tromholt, B. Andreasen, and F. C. Krebs, Stability of polymer solar cells, Adv. Mater. 24, 580 (2012).

[21] S. Strohm, F. Machui, S. Langner, P. Kubis, N. Gasparini, M. Salvador, I. McCulloch, H.-J. Egelhaaf, and C. J. Brabec, P3HT: Non-fullerene acceptor based large area, semi-transparent PV modules with power conversion efficiencies of 5\%, processed by industrially scalable methods, Energy Environ. Sci. 11, 2225 (2018).

[22] E. Destouesse, M. Top, J. Lamminaho, H.-G. Rubahn, J. Fahlteich, and M. Madsen, Slot-die processing and encapsulation of non-fullerene based ITO-free organic solar cells and modules, Flex. Print. Electron. 4, 45004 (2019).

[23] A. S. Gertsen, M. Fernandez Castro, R. R. Søndergaard, and J. W. Andreasen, Scalable fabrication of organic solar cells based on non-fullerene acceptors, Flex. Print. Electron. 5, 14004 (2019).

[24] S. Song, K. T. Lee, C. W. Koh, H. Shin, M. Gao, H. Y. Woo, D. Vak, and J. Y. Kim, Hot slot die coating for additivefree fabrication of high performance roll-to-roll processed polymer solar cells, Energy Environ. Sci. 11, 3248 (2018).

[25] S.-I. Na, Y.-H. Seo, Y.-C. Nah, S. Kim, H. Heo, J.-E. Kim, N. Rolston, R. H. Dauskardt, M. Gao, Y. Lee, and D. Vak, High performance roll-to-roll produced fullerene-free organic photovoltaic devices via temperature-controlled slot Die coating, Adv. Funct. Mater. 29, 1805825 (2019).

[26] S. Wheeler, F. Deledalle, N. Tokmoldin, T. Kirchartz, J. Nelson, and J. R. Durrant, Influence of Surface Recombination on Charge-Carrier Kinetics in Organic Bulk Heterojunction Solar Cells with Nickel Oxide Interlayers, Phys. Rev. Appl. 4, 24020 (2015).

[27] Z. Yu and L. Sun, Recent progress on hole-transporting materials for emerging organometal halide perovskite solar cells, Adv. Energy Mater. 5, 1500213 (2015).

[28] B. Tremolet de Villers, C. J. Tassone, S. H. Tolbert, and B. J. Schwartz, Improving the reproducibility of P3HT:PCBM solar cells by controlling the PCBM/cathode interface, J. Phys. Chem. C 113, 18978 (2009).
[29] E. L. Ratcliff, B. Zacher, and N. R. Armstrong, Selective interlayers and contacts in organic photovoltaic cells, J. Phys. Chem. Lett. 2, 1337 (2011).

[30] X. Fan, W. Nie, H. Tsai, N. Wang, H. Huang, Y. Cheng, R. Wen, L. Ma, F. Yan, and Y. Xia, PEDOT:PSS for flexible and stretchable electronics: Modifications, strategies, and applications, Adv. Sci. 6, 1900813 (2019).

[31] A. L. F. Cauduro, R. dos Reis, G. Chen, A. K. Schmid, H. G. Rubahn, and M. Madsen, Work function mapping of $\mathrm{MoOx}$ thin-films for application in electronic devices, Ultramicroscopy 183, 1339 (2017).

[32] R. Søndergaard, M. Hösel, D. Angmo, T. T. Larsen-Olsen, and F. C. Krebs, Roll-to-roll fabrication of polymer solar cells, Mater. Today 15, 36 (2012).

[33] K. Liu, T. T. Larsen-Olsen, Y. Lin, M. Beliatis, E. Bundgaard, M. Jørgensen, F. C. Krebs, and X. Zhan, Rollcoating fabrication of flexible organic solar cells: Comparison of fullerene and fullerene-free systems, J. Mater. Chem. A 4, 1044 (2016).

[34] T. T. Larsen-Olsen, R. R. Sondergaard, K. Norrman, M. Jorgensen, and F. C. Krebs, All printed transparent electrodes through an electrical switching mechanism: A convincing alternative to indium-tin-oxide, silver and vacuum, Energy Environ. Sci. 5, 9467 (2012).

[35] S. Shoaee, M. Stolterfoht, and D. Neher, The role of mobility on charge generation, recombination, and extraction in polymer-based solar cells, Adv. Energy Mater. 8, 1703355 (2018).

[36] Y. H. L. Lin, M. A. Fusella, and B. P. Rand, The impact of local morphology on organic donor/acceptor charge transfer states, Adv. Energy Mater. 8, 1702816 (2018)

[37] F. Zhao, C. Wang, and X. Zhan, Morphology control in organic solar cells, Adv. Energy Mater. 8, 1703147 (2018).

[38] S. Berny, L. Tortech, M. Véber, and D. Fichou, Dithiapyrannylidenes as efficient hole collection interfacial layers in organic solar cells, ACS Appl. Mater. Interfaces 2, 3059 (2010).

[39] C. J. Brabec, N. S. Sariciftci, and J. C. Hummelen, Plastic solar cells, Adv. Funct. Mater. 11, 15 (2001).

[40] L. H. Rossander, N. K. Zawacka, H. F. Dam, F. C. Krebs, and J. W. Andreasen, In situ monitoring of structure formation in the active layer of polymer solar cells during roll-to-roll coating, AIP Adv. 4, 87105 (2014).

[41] L. H. Rossander, H. F. Dam, J. E. Carlé, M. Helgesen, I. Rajkovic, M. Corazza, F. C. Krebs, and J. W. Andreasen, Inline, roll-to-roll morphology analysis of organic solar cell active layers, Energy Environ. Sci. 10, 2411 (2017).

[42] B. Y. Finck and B. J. Schwartz, Drift-Diffusion Studies of Compositional Morphology in Bulk Heterojunctions: The Role of the Mixed Phase in Photovoltaic Performance, Phys. Rev. Appl. 6, 54008 (2016).

[43] B. Y. Finck and B. J. Schwartz, Understanding the origin of the S-curve in conjugated polymer/fullerene photovoltaics from drift-diffusion simulations, Appl. Phys. Lett. 103, 53306 (2013).

[44] F. Verbakel, S. C. J. Meskers, and R. A. J. Janssen, Electronic memory effects in diodes of zinc oxide nanoparticles in a matrix of polystyrene or poly(3-hexylthiophene), J. Appl. Phys. 102, 83701 (2007). 
[45] D. A. Melnick, Zinc oxide photoconduction, an oxygen adsorption process, J. Chem. Phys. 26, 1136 (1957).

[46] Q. H. Li, T. Gao, Y. G. Wang, and T. H. Wang, Adsorption and desorption of oxygen probed from $\mathrm{ZnO}$ nanowire films by photocurrent measurements, Appl. Phys. Lett. 86, 123117 (2005).

[47] P. A. C. Quist, W. J. E. Beek, M. M. Wienk, R. A. J. Janssen, T. J. Savenije, and L. D. A. Siebbeles, Photogeneration and decay of charge carriers in hybrid bulk heterojunctions of $\mathrm{ZnO}$ nanoparticles and conjugated polymers, J. Phys. Chem. B 110, 10315 (2006).

[48] M. R. Lilliedal, A. J. Medford, M. V. Madsen, K. Norrman, and F. C. Krebs, The effect of post-processing treatments on inflection points in current-voltage curves of roll-to-roll processed polymer photovoltaics, Sol. Energy Mater. Sol. Cells 94, 2018 (2010).

[49] Y. Wang, D. Qian, Y. Cui, H. Zhang, J. Hou, K. Vandewal, T. Kirchartz, and F. Gao, Optical gaps of organic solar cells as a reference for comparing voltage losses, Adv. Energy Mater. 8, 1801352 (2018).

[50] S. S. Hegedus and W. N. Shafarman, Thin-film solar cells: Device measurements and analysis, Prog. Photovoltaics Res. Appl. 12, 155 (2004).

[51] W. J. Potscavage, S. Yoo, and B. Kippelen, Origin of the open-circuit voltage in multilayer heterojunction organic solar cells, Appl. Phys. Lett. 93, 193308 (2008).

[52] G. Wang, H. Yoo, S.-I. Na, T.-W. Kim, B. Cho, D.-Y. Kim, and T. Lee, Electrical conduction through self-assembled monolayers in molecular junctions: $\mathrm{Au} /$ molecules/ $\mathrm{Au}$ versus $\mathrm{Au} / \mathrm{molecule/PEDOT:PSS/Au,} \mathrm{Thin} \mathrm{Solid} \mathrm{Films}$ 518, 824 (2009).

[53] G. Zhang, S. A. Hawks, C. Ngo, L. T. Schelhas, D. T. Scholes, H. Kang, J. C. Aguirre, S. H. Tolbert, and B. J. Schwartz, Extensive penetration of evaporated electrode metals into fullerene films: Intercalated metal nanostructures and influence on device architecture, ACS Appl. Mater. Interfaces 7, 25247 (2015).

[54] M. A. Green, Y. Hishikawa, E. D. Dunlop, D. H. Levi, J. Hohl-Ebinger, and A. W. Y. Ho-Baillie, Solar cell efficiency tables (version 51), Prog. Photovoltaics Res. Appl. 26, 3 (2018).

[55] D. Gotleyb and R. Shikler, Role of the Dielectric Nature of the Transparent Contact in Charge Injection and Collection in Organic Optoelectronic Devices, Phys. Rev. Appl. 12, 14029 (2019).

[56] J. Melskens, B. W. H. van de Loo, B. Macco, L. E. Black, S. Smit, and W. M. M. Kessels, Passivating contacts for crystalline silicon solar cells: From concepts and materials to prospects, IEEE J. Photovoltaics 8, 373 (2018).

[57] D. M. Stevens, J. C. Speros, M. A. Hillmyer, and C. D. Frisbie, Relationship between diode saturation current and open circuit voltage in poly(3-alkylthiophene) solar cells as a function of device architecture, processing conditions, and alkyl side chain length, J. Phys. Chem. C 115, 20806 (2011).

[58] See Supplemental Material at http://link.aps.org/supple mental/10.1103/PhysRevApplied.14.034067 for additional experimental results. 